\title{
The Energy Sector and the Internet of Things - Sustainable Consumption and Enhanced Security through Industrial Revolution 4.0
}

\author{
Awang Dzul-Hashriq Dharfizi \\ School of International Studies \\ College of Law, Government and International Studies \\ Universiti Utara Malaysia \\ Corresponding author: adhd@uum.edu.my \\ DOI: https://doi.org/10.32890/jis2018.14.7
}

Received: 4 January 2018

Revised: 8 June 2018

Accepted: 9 August 2018

\begin{abstract}
With integration between machine automation and data being the hallmark of industrial revolution 4.0, the resilience of energy infrastructure in modern economy has taken a new significance. The study aims at discussing the potential and examining the impacts of the Internet of Things (IoT), which are smart devices with embedded sensors and connectivity, enabling data exchange to the energy sector. This technology contributes towards enhancing industry's sustainable practices through the industrial internet of things. With data from the "edge of the grid," these sensors assist in efficient energy consumption, providing constant monitoring for the regulatory authority, particularly on pollutant emissions. IoT technology may complement the national electric smart-grid, enhancing its reliability by feeding these raw data into machine learning neural network for the optimal operation. All these technologies shall complement one another, as Malaysia transform from a net energy exporter into an energy importer. Practicing efficient energy consumption can reduce this external dependency, and enhance national energy security. This paper derives statistical data sourced from the Energy Commission and technical data from publications of other scholars. On smaller scale, IoT implementation in manufacturing plants may resulted in $15 \%$ operating cost reduction. The benefits on national level implementation however remains unknown.
\end{abstract}

\section{Introduction}

The story of industrial revolutions is an epic tale of energy manipulation, technological refinement and the resulting symbiotic interdependence between the two. One of the major hallmark of the first industrial revolution is the introduction of the steam engines which enable the conversion and utilization of energy harvested from the boiler connected with pistons to perform mechanical works. These steam-powered machines eventually replaced most of the manual labours (much to the discontent and protests by the Luddites) and enable bigger production output, cheaper goods and further improvement of societal 
living standards. The second industrial revolution on the other hand was among other things marked by the proliferation of electricity and the advent of the petroleum industry. Automobiles were introduced to the masses, leading to general increase on the consumption of gasoline as well as other refined hydrocarbon products. Domestic supply of natural gas as well as electricity to homes becomes common in larger cities. The subsequent proliferation of electricity supply to homes and further development in the field of electronics have led to the birth of digital revolution, also known as the third industrial revolution in the 1960s. The creation of transistors, and later microprocessors as the replacement for vacuum tubes has made the manufacturing of digital computer to be economical and portable leading to its widespread adoption (Drath \& Horch, 2014; Ramamurthy \& Jain, 2017; Schwab, 2016). By this point, access to energy is ubiquitous in most developed world and by the last decade of the $20^{\text {th }}$ century, internet gained worldwide proliferation, accelerating transfer of knowledge and ideas and facilitating inter-continental communication

While Malaysia may have missed out on the first two industrial revolutions, as a young, sovereign and independent nation, the country benefits much from the third industrial revolution. By incorporating automated manufacturing, especially in the electronics sector and embracing the digital revolution, Malaysia's economic growth expanded from RM 53.308 billion in 1980 to around RM 1.107 trillion in 2014, a 2,207.57\% growth within a period of 36 years, with an average of $9.30 \%$ annual growth (Jabatan Perangkaan Malaysia, 2015). Within the same period however, the final energy demand nationwide has increased by $719.87 \%$, from 6,385 thousand tons of oil equivalent (ktoe) in 1980 to 57,219 ktoe in 2016, signifying an average of $6.37 \%$ average annual demand growth (Suruhanjaya Tenaga, 2017b). This is evident as shown in the following Figure 1.

With ever increasing, insatiable needs for energy by the growing population burdened by the increasing energy cost and dwindling indigenous non-renewable fuel resources, it is essential to address and identify potential concerns relevant to the issue. The society has becoming more dependent on complex machineries which require constant energy supply for their operations, from smartphones to the banking services. This article aims at discussing the impacts, challenges and opportunities presented by the Fourth Industrial Revolution in the energy sector, focusing on sustainable energy consumption, emission control and energy efficiencies utilizing the idea centred upon the Internet of Things (IoT).

This article adopted a documentary-based research method by utilising prior findings from primary and secondary sources. The approach is deemed necessary, considering the multidisciplinary nature of the topic itself, ranging from policy issues on energy, to the latest technical advancement on IoT, and to avoid from re-inventing the wheel of undertaking similar research purely for the sake of veracity. The statistics on national energy consumption as provided by the Malaysia Energy Commission is one of the most indispensable resource for this purpose. It assists in identifying trends and patterns which have developed overtime. a useful tool for longitudinal or even cross-sectional comparison. Other technical data however are obtained from previous researches conducted by contemporary scholars in their respective field. 


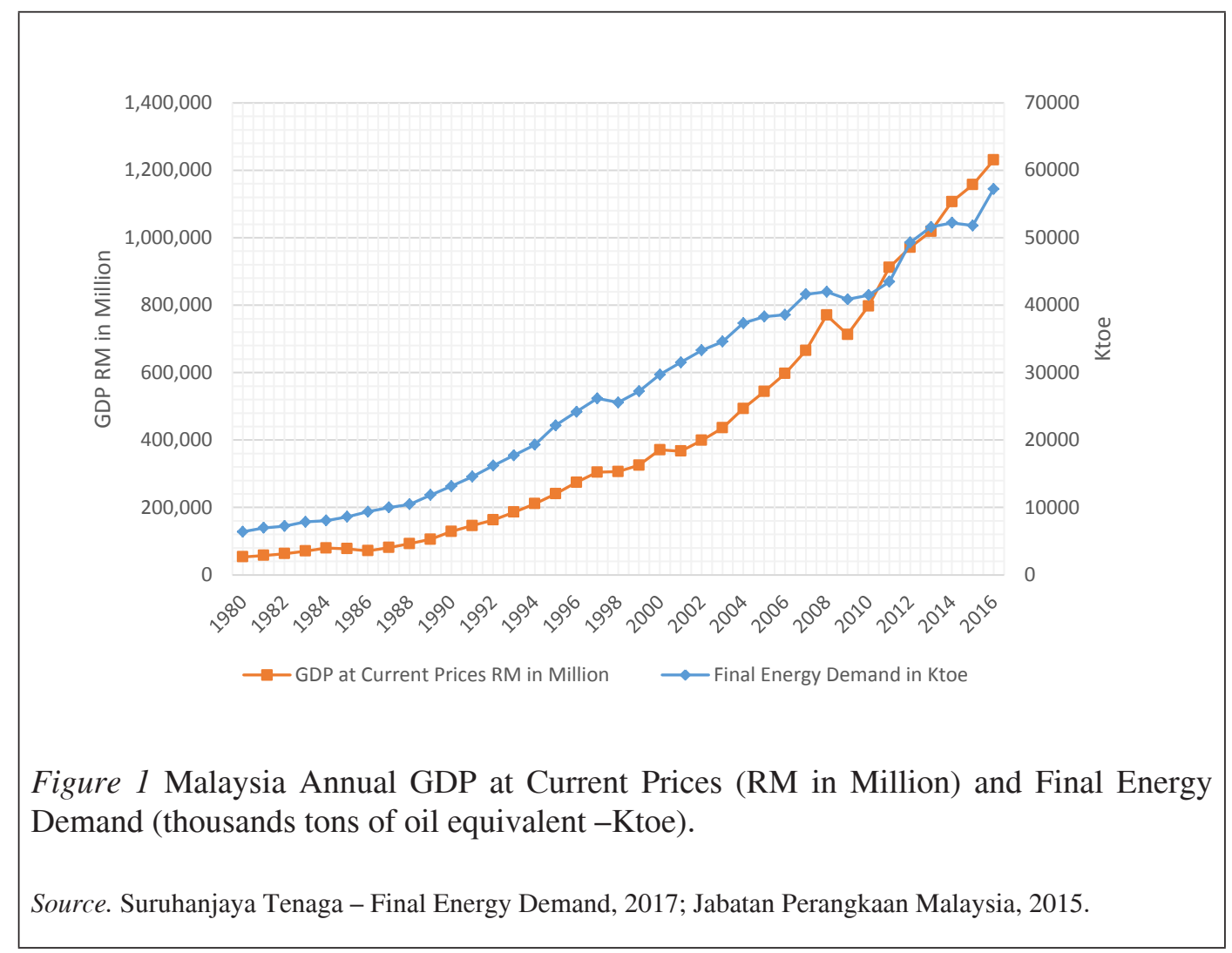

\section{Industrial Revolution 4.0 and the Internet of Things}

Building upon the foundation created through the proliferation of computerised systems and global internet network, the Fourth Industrial Revolution or Industrial Revolution 4.0 (IR4.0) proposed, among other things further integration of cyber-physical systems leading towards enhanced machines automation. The term was first introduced in 2011 during the Hannover Fair in Germany, encompassing several other key concepts apart from the aforementioned cyber-physical amalgamation which includes Smart Factory, systemic selforganizations and adaptation to human needs, establishment of new systems to cater product development and services, as well as individualised distribution and procurement processes. (Lasi, Fettke, Kemper, Feld, \& Hoffmann, 2014). A year later in 2012, a similar concept with broader application was also proposed by General Electric in the United States under the banner Industrial Internet although this leads to more confusion instead of increased transparency (Drath \& Horch, 2014).

For the energy sector, there are four main levers or components of IoT in energy savings. These are inter-asset transparency, energy consumption monitoring and control on 
elementary level, real-time energy consumption optimization and full system optimisation (A.T.Kearney, 2015). Inter-assets transparency can be achieved through devices interconnection which shall highlights the assets availability for optimal and maximization of utilisation. A common example would be the car-sharing platform for car-pooling, such as those of Uber or Grab. A passenger may utilise free assets (registered driver/car) to move from point A to point B rather efficiently instead of driving his own car and having to deal with other issues such as parking spaces. The second stage would include which can be demonstrated through smart-metering or remotely-connected thermostats/air-conditioning. Data collected through sensors in the second stage shall be subjected to further analysis through the Big Data algorithms, identifying historical use to plan optimal operations in real-time. Real-time optimisation of aircraft engines based on multiple data points harvested though thousands of sensors will be a prime example of this scenario. In the final stage, a full, systemic automation will take place where inter-connected objects or devices will communicate and adapt autonomously for optimal data consumption. Whereas it has yet to be fully realised, integration between fully autonomous vehicular controls systems with urban traffic management system would be a practical example. Autonomous vehicles will be connected with the traffic system which will analyse the traffic situation for traffic jams, diversion or traffic accidents and consequently direct or suggest and execute the most energy efficient route between two points in absence of human intervention.

From the consumer side, most of these cyber-physical integration shall be in the form of the Internet of Things. The Moore's Law has observed, predicted and dictated that the number of transistor in integrated circuit (and consequently, computing powers) shall double every 18-24 months (Moore, 1965). More efficient production has made the technology to be sufficiently cheap for mass adoption of digital technology, further accelerating its development by the industry and has now rendered it to be economically feasible, to have each devices to be connected to the internet enabling remote control by the users or autonomous actions according to present parameters, interacting with the environment contextually. Through the incorporation of smart sensors and better systemic analytical capabilities, greater communication and data-driven services may now be possible, offering improved quality of life (Schwab, 2016).

The Institute of Electrical and Electronics Engineers (IEEE) defined IoT as "a network that connect uniquely identifiable 'Things' to the Internet. The 'Things' have sensing/actuation and potential programmability capabilities. Through the exploitation of unique identification and sensing, information about the 'Thing' can be collected and the state of the 'Thing' can be changed from anywhere, anytime by anything" (Minerva, Biru, \& Rotondi, 2015, p.71). This in essence is the manifestation of Internet of Things (IoT), where the Internet acts as the backbone infrastructure which connects machines, appliances and people (Ramamurthy \& Jain, 2017). Through embedded sensors and actuators, these devices may transmit collected information through the internet, or even perform computational operations and make intelligent decisions in absence of human physical presence or intervention. Despite the lack of critical needs for human physical presence, in essence, IoT still aims at providing connectivity for anyone to anything regardless of temporal and spatial limitations (Khan, 
Khan, Zaheer, \& Khan, 2012). In layman terms, IoT is the idea where every powered devices may be connected to the internet, capable of utilising its own embedded sensors or actuators to gather data and transmit information which can be utilised by the end user.

Proliferation of IoTs shall resulted in the creation of newly connected ecosystems around software platforms as human-machine interface, leading to greater humans-machines collaboration resulting to better productivity and more efficient utilization of resources. Consequently, the same time the technology shall also help in reducing the risk of human errors and the need for their intervention, thus reducing the down-time of the machines, a cyclical sequence leading to a more efficient resource utilisation. These machines may range from those as complex as the machines along the assembly lines in manufacturing plants to smart electrical appliances in domestic homes. The proponent of IoT has presented numerous scenario how humanity may benefits from the technology. These range from increased resources utilization efficiencies including enhanced transparency, improved quality of life, positive impacts on the environment, and lowering the cost of service delivery (Schwab, 2016). Certainly not all of these will be applicable to the energy sector, although enabling enhanced and a more transparent resource utilization is a positive step towards it.

\section{Internet of Things and the Energy Sector}

As discussed, the energy sector may well benefit from IoT through efficient and transparent resource utilization. It is known that hydrocarbon resources such as petroleum and natural gas as well as coal are finite and efficient resource management is essential, but in this context, the most relevant resource being discussed is the electricity energy, the output of power-plants nationwide. Whereas electricity is a versatile form of energy, it suffers from several weaknesses. One of it is its fluctuating demand depending on times of the day and even season, including football season, as observed through the "halftime kettle effect" (Zubi, Dufo-López, Carvalho, \& Pasaoglu, 2018). In more temperate climate, demands for energy may spike during winter for heating, or summer for air conditioning. Even on daily basis, demand for electricity peaks during the morning and in the early evening hours before declining towards the midnight and early morning hours (Gaur, Kumar, Agarwal, Baba, \& Soonee, 2017). In Malaysia, the load curve for electric consumption recorded peak demands by 7.00 am and $9.00 \mathrm{pm}$ for domestic consumer and peaking slightly before and after midday lunchtime for commercial consumer respectively (Ponniran, Nur Azura, \& Joret, 2012).

Fluctuating and even sudden demands for electric power will over-load the national electric grid and may resulted in blackouts or brownouts, leading to further loss in economic activities (Orcutt, 2010). As electricity is consumed the instant it was generated, it is essential for the power producing companies to be able to anticipate demands, generate, maintain and supply electricity sufficiently optimal. And whereas storage of its raw fuels or potential energy in the form of hydroelectric dam exist, the storage solutions for electricity on mass, industrial scale remains elusive in absence of new breakthrough in battery technology. The ability to store generated electricity for later use is also a challenge for renewable energy (Ecofys, 2014). 
This shortcoming in energy storage solutions call for a way to monitor energy demand in real-time, so the power producers may respond and react based on current energy needs. As necessity is often said to be the mother of invention, thus, the genesis of the smart-grid concept, with its early stage of smart-meter development harken back from the 1970s before experiencing wider adoption in the 1980s (Tuballa \& Abundo, 2016). Data transmission obtained through these sensors enable the power producers to monitor the distributed energy generation through remote reading facilities, and make demand prediction based on historical energy generation and consumption data. Through smart-metering, power outages may be prevented by enforcing energy usage threshold upon customers during the period of low energy supply (Bayindir, Colak, Fulli, \& Demirtas, 2016). This demonstrates that the idea of integrating sensors and data through integrated network for enhanced economic or operational efficiency is not a new of novel concept.

In Malaysia, the idea and intention of implementing smart metering and smart grid concept dated back from 2009, when the Smart Grid Test System was implemented in three selected zones, namely Bayan Lepas in the north, Bukit Bintang in the central region and Medini in the southern part of the peninsula. Each of these zones also represents the industrial, commercial and green field areas. Being the largest of the three power utility companies operating in Malaysia, it is important for TNB to be able to cater to the growing needs while maintaining sustainable operational practice. In essence, its plan of developing smart grid was actually driven by four factors, namely aging, legacy infrastructure including those in the generation, transmission and distribution subsystems, the risk for energy, financial and environmental crisis (Rakob, 2010).

Although smart-grid and smart-metering do not exactly represent Internet of Things as envisioned in the IR 4.0 Hannover Fair, it encapsulates the very idea of integrating sensors into devices and utilising those sensors for data collection and communication, either between devices or customer and devices, thorough a network to enhance the quality of service delivery. It is therefore not inaccurate to consider the smart-grid concept to be a pre-IoT breakthrough where the energy sector has greatly benefits from. It offers better method of fault locating, sectionalisation and isolation of faulty section, as well as supply restoration upon sectionalisation, thus empowering the service providers. It also empowers and enhances the customers' experiences by offering real-time information for energy consumption and enable their participation in renewable energy initiatives through the Feed-in-Tariff (FiT) programme (Energy Commission, 2015; Rakob, 2010). As its software interface gets improved (subject to future improvement and refinement by power producers), it is not impossible for the smart-meter to be directly connected to the internet enabling direct monitoring by the end-user. It may also open opportunities for more third-party devices to be designed for direct communication with the smart-meter, with features to shut itself down based on several additional parameters such as human presence, overall grid-load and the price of electricity at any given moment. Smart-metering may also enable the power and utility companies to render flexible pricing mechanism, dependent on the time or period of the day to prevent peak demand and unnecessary loads to the grid, although such decisions will require prior consensus and approval from all stakeholders, especially the customers. 


\section{Home Automation}

The opportunity to have warm, boiled water, and hot toasty bread ready upon breakfast time or to arrive in cold, air-conditioned house after long work-days with the laundry washed would be dream-like for many people. Whereas for some devices, the inbuilt timer function may offer limited ability for pre-programmed operations, similar options may not be available to other appliances. Furthermore, it is neither prudent nor economical, either financially, environmentally to actually leave the air-conditioning running for the whole day, and dependency on built-in timer feature may be rather problematic for long absence from home. This is where the idea of home automation through smart devices with IoT functions may offer a more convenient and practical solution.

The creation of Smart Homes or Home Automation may be realised through the incorporation of technology within the domestic settings to provide convenience, comfort, security and in this context particularly, energy efficiency for its occupants. Undoubtedly, adding these smart functions may enhance the quality of life, as the occupants of the house may therefore be more informed of their general energy consumption behavioural patterns and have the ability to remotely micro-manage the functions and roles their electrical devices as needed. Reacting to empty rooms, these IoT smart appliances may enable the turning off lights and air conditioning thus reducing unnecessary wastage. Data gathered from the sensors may have a significant and lasting impact on future energy consumption patterns upon subjected to further analysis, which also enables the owners to partake preventive and proactive maintenance before any real damage occurs (Stiner, 2017). From managing the powerutilization consumed by each of their inter-connected appliances, to the ability to monitor the physical surrounding of their homes, the homeowners thus have further control over their properties.

In the U nited States, major energy consumption in a domestic and residential settings include for the purpose of general heating or cooling at 56\%, water heating at $14 \%$, lighting and other appliances at $15 \%$ each respectively (Mclellan, n.d.). Owing to climate differences, the breakdown is rather different in Malaysia where in 2011, the residential sector in Malaysia recorded a 7.8 Mtoe (million tons of oil equivalents) of energy consumption. Excluding the $15 \%$ (or 1.17 Mtoe) energy consumption for LPG and cooking gas utilization, the remaining 6.63 Mtoe of electrical energy utilization can be broken down to $4 \%$ for illumination $(0.312$ Mtoe), $9 \%$ for washing machine (0.702 Mtoe), $10 \%$ for air conditioning (0.78 Mtoe) and $18 \%$ for refrigeration (1.404 Mtoe) among other things (Mangruwa, Salim, Mahdzir, \& Khalid, 2015).

Since 1978, the residential and commercial sector in Malaysia has recorded a $1030.48 \%$ of final energy demand, or an average of $27.12 \%$ annual growth over the period of 38 years (Suruhanjaya Tenaga, 2017a). Parallel with population growth and with increased utilization of electrical and electronic appliances in daily life, these figures is expected to grow overtime. Whereas technological advancement may have resulted in a more refined 
and energy efficient devices, the number of electric and electronic appliances has been on the increase. Thus, the idea of home automation through the reconceptualization of smart homes and incorporation of smart devices through IoT may provide an optimal solution to address this issue of increasing domestic energy demands.

As previously discussed, incorporating sensors in living spaces which will detect human presence to trigger relevant functionalities is a step towards the right direction. So does the integration of cross-platform compatibilities, enabling user control through computers, smartphones or even smartwatches. The latter is an option offered by a Chinese corporation, Xiaomi following the introduction of its latest smartwatch model, Amazfit Verge in September $17^{\text {th }}$, 2018. As a smart home device controller, the smartwatch allows its user to control their smart gadgets through watch interface. Previously, the company has been offering a range of smart devices and the introduction of this smartwatch into its IoT range is just another way of enhancing its customers' experiences and utilities as well as enriching the existing device/platform ecology. Other smart devices and gadgets which are part of their IoT and smart-home lines which may be accessible and controllable from the new smart-watch include robot vacuum cleaner, water purifier, temperature and humidity sensor, air conditioner smart rice cooker and their lines of smart switch/socket (John, 2018).

By utilising these smart devices and enabling enhanced, cross-platform control by the users, research has shown that it has resulted in significant energy savings. $40 \%$ of energy can be saved from lighting alone although a $18.7 \%$ decrease of overall energy consumption is more accurate for a single residential building (Tejani, Al-Kuwari, \& Potdar, 2011). Another research demonstrated that an energy savings between $14 \%$ and $30 \%$ is possible through the incorporation of IoT-based, smart appliances (Moreno, Ubeda, Skarmeta, \& Zamora, 2014). Evidently the usage patterns in Malaysian residential areas may differ due to the weather factor and thus the lack of heating needs, among other things. This does further justify future research for its utilisation and practical savings for general Malaysian households.

\section{Smart-Digital Factories}

It was argued that by 2020, almost one-third of IoT investment will take place in APeJ (Asia-Pacific excluding Japan) region, while the United States manufacturing sector will account to $15 \%$ of total IoT purchases ("The Internet of Things in manufacturing: benefits, use cases and trends," 2017). Introducing IoT to the manufacturing sector would means that the entire supply chain will be more dependent on coordination across every level, from logistics, to supplier to end user as well as everything in between. With a potential of unleashing up to USD 6.2 trillion in new global economic value by 2025, it is a vast market to tap into (Riley, 2016). Thus, in order to remain competitive, Malaysia is not to be excluded from these phenomena and rather should be part of the movement, the next stage of evolution within this industrial revolution. 
Despite the move to a more service-oriented economy, the manufacturing sectors remain to be a dominant contributor to Malaysian economy. In 2017, it represents $23 \%$ of the national GDP amounting to approximately RM 271 billion, while recording a 6.0\% growth compared to the previous year (Jabatan Perangkaan Malaysia, 2018). From the energy perspective, the industrial sector recorded a $604.75 \%$ increment on final energy demand between 1978 and 2016, a 15.91 average annual growth. In 2016, it recorded 16.019 Mtoe in final energy demand (Suruhanjaya Tenaga, 2017a).

Rising energy cost, changing customer behavior and expectations as well as increasing environmental awareness and regulatory measures for emission control necessitated the adaptation for factory operations to be sustainable. This resulted in the practice of green manufacturing and energy efficient production processes. In simplest form, it can be realised by integrating the energy data into the production management stage, installing smart meters at machine level. As data exchange constitute key components of smart factories, these data could represent various parameters including production status, energy consumption behavior, material and inventory movements, customer orders and feedback as well as supplier's data. It was envisioned that the next generation smart factories may even be able to respond to market conditions in real-time, adjusting the production rate accordingly (Shrouf, Ordieres, \& Miragliotta, 2014; "The Internet of Things in manufacturing: benefits, use cases and trends," 2017).

Sustainable energy management in smart factories was proposed as a four-phase steps by some researchers. It started through better understanding of the production processes followed by further evaluation on energy management. In the second stage, embedded sensors in the selected assets, machineries or devices shall monitor, gather and analyse the energy consumption in real-time, based on existing practices as well as limitations and these data will be integrated into the assets to improve energy efficiency in the third stage, as decided by the decision-makers. Finally, in the last stage is integrating the relevant energy data into the production management practice (Shrouf et al., 2014). This in essence encapsulates the sustainability aspects of smart factories through efficient energy management programme.

Fast-paced and ever-changing market situation demanded the manufacturing and production sector to be equally dynamic in their response. Ideally, smart factories shall therefore be able to collect and analyse data from the internet pertaining to the customers' needs and preferences, and in return providing them with sustainable products and services. This shall result in continuous refinement of good produced and provide a richer producer-market experience, as the manufacturers will be able to obtain real-time feedback as production runs, and the consumers will receive products to their standards.

Smart factory may also benefit the IoT technology by incorporating networked-sensors in their inventory process. It shall enable the business owners to monitor their existing stocks, the movement of their goods across factories and storage warehouses which may be operating worldwide. By integrating and analysing the inventory data with the available market and supplier data, the business owners and factory operators may be able to synchronize the 
purchase and movement of inbound raw materials needed with the most optimal pricing (Riley, 2016). Adjusting the production rate with the inventory data and market pricing at real time may contributes in reducing wastage, in terms of raw materials, working manhour, and consequently energy consumed by the factory during operating hours.

The qualities of quick, flexible adaptability to market conditions for optimal and sustainable factory operation are not only the benefits of a smart factory, but also a gateway to a digital factory operations. Digital factory is a concept comprised of an amalgamation of various interdependent aspects such as optimization of factory assets, proactive and prescriptive machinery maintenance, enhanced lifetime values of machines, big-data predictive modelling to assist with manufacturing through failure avoidance via preventive maintenance as well as incorporation of 3D printing technology as well as other IoT platform (Rostetter, Khoshafian, \& Adams, 2016). The incorporation of 3D printing also enables the industry to be able to provide essential, yet infrequently purchased goods and parts at lower inventory cost, as only raw materials need to be stocked and production may begin based on immediate demands. Thus, through the combination of big-data to predict demands in real-time, the manufacturing sector will be more demand-driven, decreasing the overall cost to produce and serve (Riley, 2016).

Unfortunately, finished goods are not the only output of factories. As with any industries, industrial emissions is part of the by-products and these include Sulphur Dioxide $\left(\mathrm{SO}_{2}\right)$, Nitrogen Oxide $\left(\mathrm{NO}_{\mathrm{X}}\right)$, Carbon Dioxide $\left(\mathrm{CO}_{2}\right)$ and Carbon Monoxide $(\mathrm{CO}) . \mathrm{SO}_{2}$ is a major pollutants contributing towards the formation of acid rain, whereas $\mathrm{NO}_{\mathrm{x}}$ and $\mathrm{CO}_{2}$ are known to be greenhouse gases, major contributors to global warming. However, IoT may provide a solutions through the introduction of Continuous Emission Monitoring Systems (CEMS) which continuously collect, analyse, and report the required emission data to the environmental agencies, and therefore reducing the number of field visits by the enforcement agencies (SenseGrow Inc., 2015). A study by A.T. Kearney, a management consulting firm suggests that based on present trend, implementation of IoT in the EU could lead to further +200 million tons of CO2 emission reduction (A.T.Kearney, 2015). As there are multiple $\mathrm{CO}$ sensors technology with varying costs, utilities and effectiveness, these sensors may be connected to one another through the wireless sensor networks (WSN) which may utilise either a 3G, 4G Bluetooth of WiFi connectivity for data transmission and the collected Air Quality Data can eventually be shared with the public to create awareness on air pollution issues (Paruchuri \& Rajesh, 2018). Other studies suggested that implementations of IoT in other sectors not exclusive to the manufacturing industry, could cut up to $63 \%$ from 12.1 Giga-tons of carbon emissions, whereas combining LED street lighting with smart controls may reduce $\mathrm{CO}_{2}$ emissions by 50\%-70\% (Goerlich, 2016; Jankowski, 2014).

\section{Smart Cities}

Whereas residential homes and factories represents microcosms where IoT platform may be individually implemented by each user for sustainable, energy-efficient practices, their 
combination shall lead to a wider, bigger macrocosm that is the establishment of smart cities. This is essential as cities are growing in size and population and it was projected that by $2050,70 \%$ of the world's population shall be living in cities or urban areas. Smart cities may be characterised through its "integration of technology into a strategic approach to sustainability, citizen well-being and economic development" (McCue, 2018). Yet the aforementioned definition is not the only one and neither it is fully authoritative. Another group of scholars defined smart cities as a vast concept without clear or definitive definitions among the practitioners or academia, and rather it was framed as "a place where traditional networks and services are made more flexible, efficient and sustainable with the use of information, digital and telecommunication technologies to improve the city's operations for the benefits of its inhabitants" (Mohanty, Choppali, \& Kougianos, 2016).

Nonetheless, both definition emphasised on sustainability and technological integration for increased efficiency. Based on observations of 12 smart cities, in essence, smart cities aimed at societal improvement, economic growth and environmental sustainability (Xhafa \& Barolli, 2015). Furthermore, as smart-cities aspire to utilise IoT on much larger scale, wireless, low-powered sensors would be preferable as cabling cost for each sensors citywide may be prohibitively expensive (Talari et al., 2017). The idea of smart cities enables the optimised used of resources by the city administration to overcome the challenges being faced.

While some may see high urban population density as an issue or result of urbanisation, from the energy and environmental perspective it really can be viewed as an opportunity to lower overall carbon footprints. Malaysia is one of such developing countries that is currently experiencing urban sprawl, where the rate of land consumed for urban purposes exceeds the rate of population growth, leading to inefficient and consumptive uses of land and associated resources. Eventually, this results in increased air pollution, traffic congestion, growing consumption of water and $\mathrm{CO}_{2}$ emission as well as inefficient public transportation network (Osman, Abdullah, \& Nawawi, 2012). Through denser population and concentrated development, smaller distances covered for daily commutes and by providing carbon-free public transportation system, integrated city-wide smart electric grid as well as green, energy efficient infrastructures and homes such vision of smart, green cities may be realised.

Presently, existing technology has the capacity to combine the city's assets to improved services delivery, from traffic management to parking lot, air and noise pollution control, security and surveillance or even waste management. For example, use of LED street lighting with smart controllers resulted in $80 \%$ energy savings, costing 130 billion euros in Amsterdam. While providing better sense of safety to its citizens, the smart feature enable the dimming of the lights during low traffic hours (Talari et al., 2017). Singapore's Intelligent Transport System is another example where real-time traffic information or updated congestion charges are delivered through GPS-enabled taxis and other highly integrated public transportation (Siemens, 2013). Whereas some of these features for traffic-jam avoidance or resource utilizations are not different from what is enabled from 
smartphones applications such as Waze or Uber, neither of them are centralised on local (city) level, and therefore less optimised. Extending this function to just the transportation sector and the residential area in Malaysia, significant savings can be reached in term of energy consumption. Between 1978 until 2016, the transportation sector on average has consistently represents $39.76 \%$ whereas the residential sector represents approximately $13.40 \%$ of overall final energy demand (Suruhanjaya Tenaga, 2017a). As shown in Figure 2 , this is a rather interesting development despite the population growth and the urban sprawl issues causing longer commuting time.

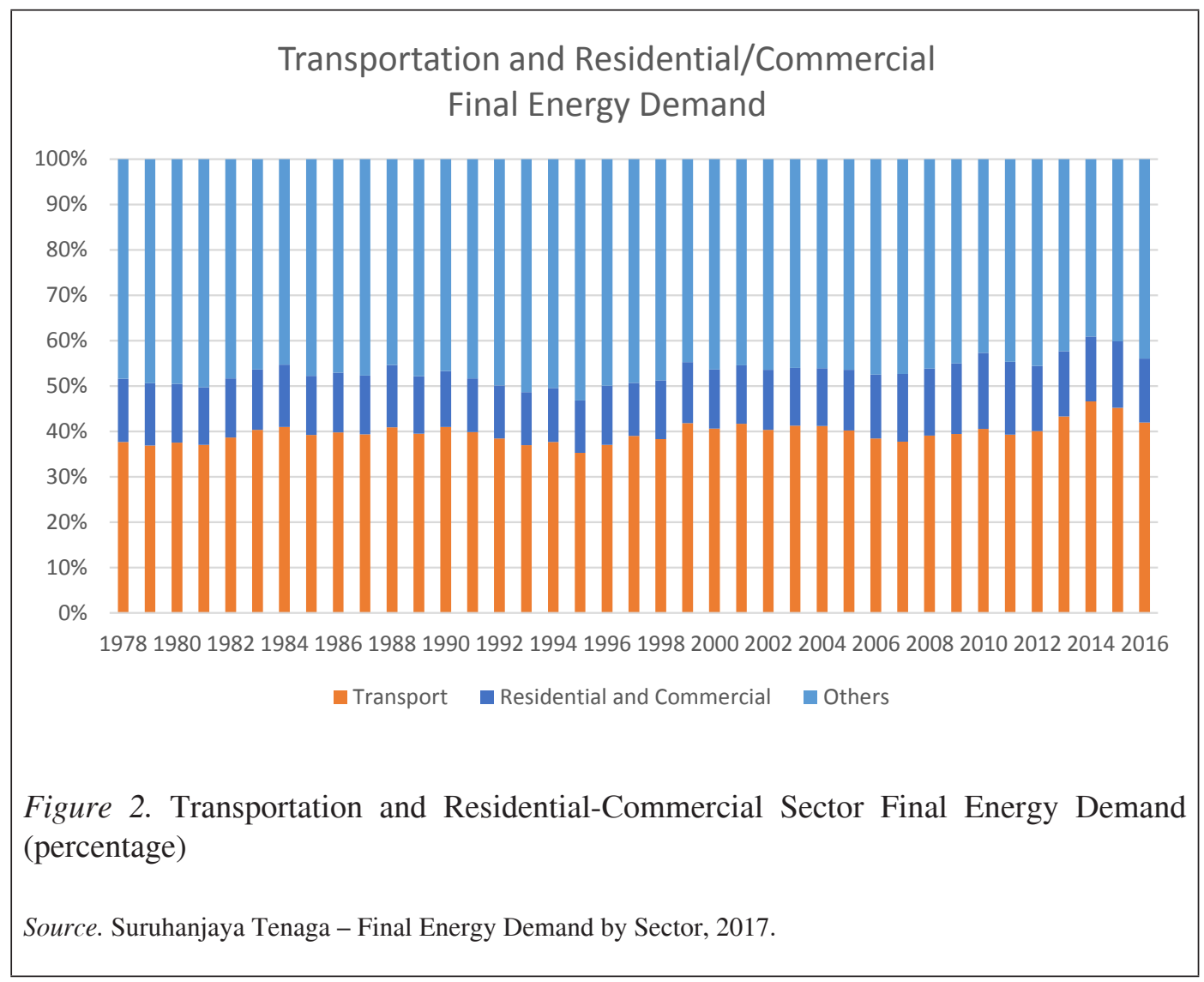

As previously mentioned, smart-cities is a macrocosm which include the components of smart-homes and smart factories. Thus, the application of IoT in smart homes and smart factories shall also be incorporated into a smart-city architecture. Apart from the aforementioned smart-appliances for energy monitoring, these homes can also be equipped with fire detection sensor or other relevant security system, which require a city-level response by the authorities. Similarly, for factories sensors monitoring noise pollution, exhaust gas emission and energy efficiency should be connected to both the regulatory authorities as well as the city administration and management for monitoring, zoning and 
future urban planning needs. Other forms and application functions of IoT in smart cities would also include smart-parking lot to monitor the movement and distribution of motor vehicles, traffic management to reduce resource wastage due to traffic jams (Mohanty et al., 2016; Talari et al., 2017). Although its direct effects may be less apparent, efficient traffic and parking management will certainly reduce the gasoline consumption by the transportation sector, while at the same time reducing air pollution generated by idling vehicles. The following Figure 3 demonstrates the possible extent of IoT integration and applications in a smart city.

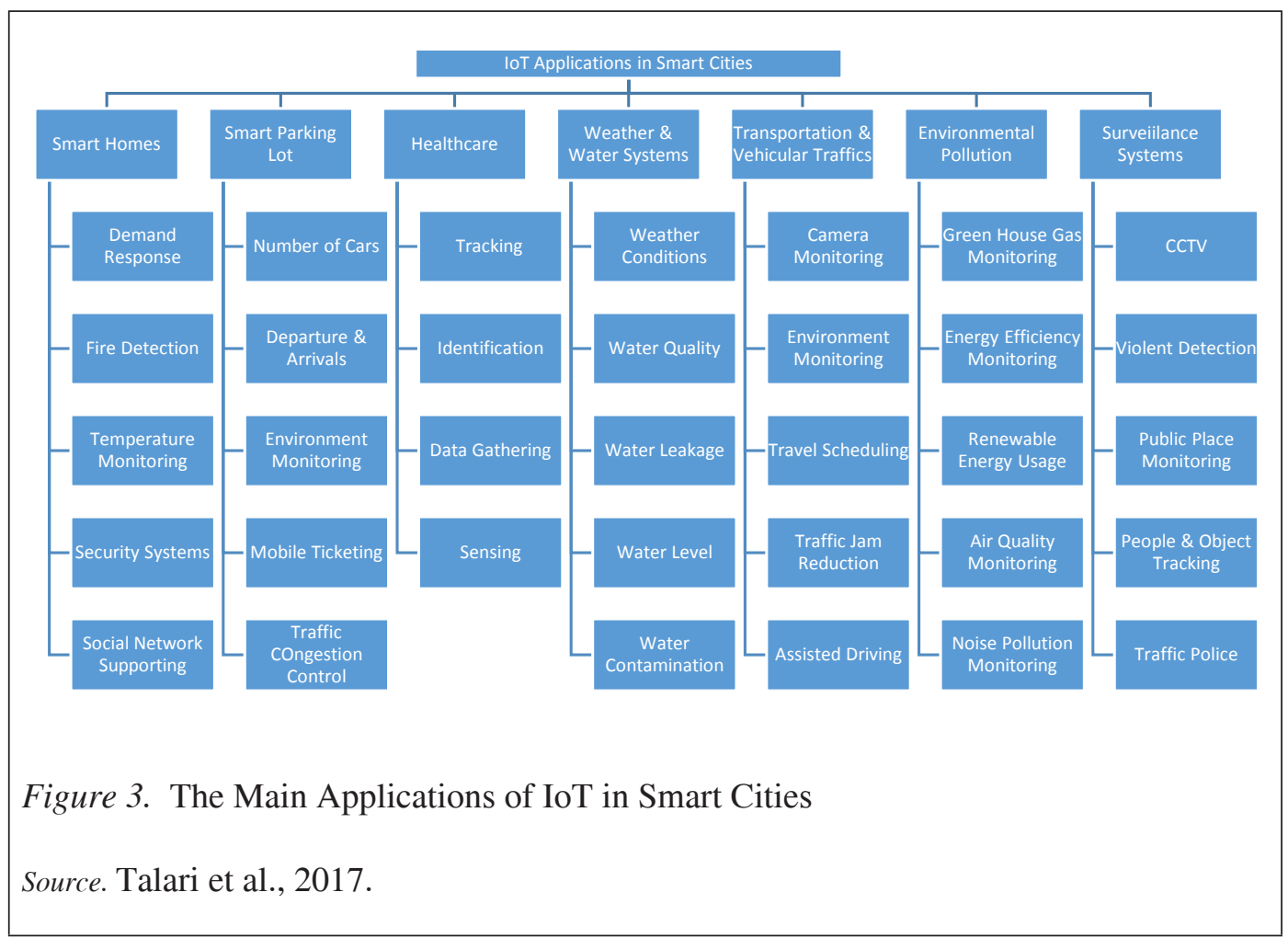

By utilising digital platforms such as the internet and SMS, residents and communities in Chicago City and its South Side Neighbourhood have been cooperating with the law enforcement agencies to combat violent crimes through data-sharing. In New York, information sharing in open government programs between the local citizens, business owners and the local authorities assist with providing awareness, whereas in Santa Cruz, gathered data on criminal actions are analysed to predict the policing requirement and optimal police presence. Enhanced public-safety may therefore be attainable through realtime monitoring, enabling rapid emergency responses (Talari et al., 2017; Xhafa \& Barolli, 2015). Whereas not directly related to the energy sector, such integration certainly helps in preventing unnecessary deployment of assets for the purpose of crime prevention. 


\section{Challenges and other Considerations}

Despite all the benefits mentioned and discussed, the incorporations of IoT technology, either for personal, domestic use, for industries or city-wide applications certainly comes with its own set of considerations. These include, but not limited to start-up and operation costs, its efficiency, systemic redundancy and other public-safety considerations, among other things.

Cost is one major factor and consideration as smart appliances are definitely costs more than ordinary, normal electrical and electronic appliances. Thus, there is the need for each customers to carefully consider their purchase, and whether it is financially prudent to discard perfectly functioning, but "dumb" appliances in exchange for smart appliances. Mishandling of this issue might resulted in massive increase of electronic waste generated by the purchase of new devices. Thus, having these smart appliances labelled with returnof-investment details (pertaining to cost and resulting energy and monetary savings) might assist in justifying purchases. Nonetheless, this cost discrepancy may also means that only those with the means to purchase the smart devices may actually benefited the resulting savings, thus leading to wider gaps in terms of quality of life between the poor and the wealthy.

Cyber-security concern is also an issue with IoT devices. As with any connected devices, they are not invulnerable to hacking. Generated data from the sensors may be subjected to unauthorised access and abuse, especially those sent through unsecured wireless network. Malware risks on connected devices, or even on unconnected devices may result in reallife, physical catastrophe. The result of Stuxnet virus on Iranian centrifuge, affecting the supervisory control and data acquisition (SCADA) systems on the uranium centrifuges has resulted in the machines to fail and self-destruct through operations beyond design parameters (Kushner, 2013). Another example is the Trojan Horse programming by the CIA to sabotage Soviet Siberian gas pipeline, resulting in massive explosion in 1982 (Russell, 2004).

With various sensors in smart devices always collecting, generating and transmitting data, issues relating to privacy is another valid concern. This is even more pressing if the mass surveillance is conducted by the authorities, infringing the private life of their citizens. An extreme example would be the Social Credit System employed in China, where each citizens are tracked by the government and assigned with social credits which may affect their lives through travel ban, exclusion from private schools or access to jobs and bank loans. Whereas hypothetical at the moment of writing, implementations of such system nationwide by an authoritarian government does not discount the risk of systemic hacking and as the information is centralised on national level, the repercussions will be far-reaching and unimaginable. Connected databases containing sensitive information will in essence put more than a billion of Chinese citizens to identity theft, especially with the Chinese government record of being lax on data security (Chorzempa, Triolo, \& Sacks, 2018). 
Furthermore, as the devices are constantly connected, the users need to have the ability to "kill" or deactivate the sensors or RFID (Radio Frequency Identification) tags if needed to protect the network and data integrity from being exploited by an unauthorised third party (Weber, 2010).

Increased number of connected devices also suggests increased dependency on the energy sector to ensure smooth operations. The system in itself needs to be resilient to various forms of disasters and failures, whether they originated from ICT or power failure (Mohanty et al., 2016). The Carrington event of 1859, caused by geomagnetic solar flare, should it happen today will resulted in unimaginable chaos for a society so dependent on electricity and digital technology. A smaller version of this event took place in Quebec in March 1989, resulting in electrical grid failure and damaged transformers (Bell \& Phillips, 2008). Power failure in particular may leads to cascading effects as the embedded sensors of IoT stop functioning, and thus any smart city designer will have to consider these scenarios and prepare for any contingencies.

Concurrent to the dependency upon the energy sector for operation, IoT technology, as the name suggests is also dependent on the availability of internet network coverage. Despite the ever expanding internet coverage and the quality of service throughout Malaysia, it has yet to reach the penetration level equal to other basic utilities such as electricity and clean, potable tap water. As of March 2018, the level of internet penetration nationwide stands at $85.7 \%$ and $76.9 \%$ or 24.5 million populations are the users (Alias, 2018; Internet Users Survey 2017, 2017). This is to be compared to near $100 \%$ electrification rate in Malaysia (with exceptions to pockets of rural areas) and $95.7 \%$ access to piped water nationwide (Energy Watch, 2018; Jabatan Perangkaan Malaysia, 2017). Whereas a number of rural schools and residential areas are still reliant on electricity provided by the diesel-powered generator, initiatives by the government to provide these schools with solar panel has succumbed to corruption and malpractice. The price also has remained non-competitive relative to the internet service in the region, due to monopolistic practice by the internet service provider. All these issues need to be addressed as to enable common people to benefit from IoT technology, not just industries or urban populations.

\section{Conclusions and Further Steps}

In attaining sustainable energy consumption practice and trends, Malaysia must be prepared to embrace IoT, not only for the utility companies but also among the final consumers, both the domestic and industrial users. In response, the internet service provider must aim at increasing their quality of service and decrease the overall costs of operation to facilitate wider adaptability of this technology. However, careful considerations and study need to be conducted to ensure compliance within Malaysia's legal framework, particularly pertaining to security and privacy issues. Resilient infrastructures must also be in place to prevent cascading systemic failure as a result of over-dependency on digital technology. 
The IoT has undoubtedly opened a wide opportunity of harnessing the flexibility and efficiency of digital technology into our daily life. Digitizing homes and factories, even the entire city with sensors for monitoring and data collection shall enable the administrators and decision-makers to optimise its daily operation, resulting to a more efficient energy consumption and lesser emission. With the advent of the Fourth Industrial Revolution, mass adoption of IoT is inevitable. To remain economically competitive, the government must play its role to encourage its mass adoption, not only for better energy efficiency but also for optimal operations and compliance monitoring. The totality of energy shall ensure that the results of this endeavour shall be one experienced by all, through enhanced energy access by the population, lower emissions, cleaner environment and higher productivity efficiency.

\section{References}

Alias, A. (2018, March). Malaysia's internet penetration is now 85.7 per cent. New Straits Time. Retrieved from https://www.nst.com.my/business/2018/03/346978/malaysiasinternet-penetration-now-857-cent

Bayindir, R., Colak, I., Fulli, G., \& Demirtas, K. (2016). Smart grid technologies and applications. Renewable and Sustainable Energy Reviews, 66, 499-516. https://doi. org/10.1016/j.rser.2016.08.002

Bell, T. E., \& Phillips, T. (2008). A Super Solar Flare. Retrieved from http://science.nasa. gov/science-news/science-at-nasa/2008/06may_carringtonflare

Chorzempa, M., Triolo, P., \& Sacks, S. (2018). Policy Brief 18-14 China's social credit system: A mark of progress or a threat to privacy? Peterson Institute for International Economics. Retrieved from https://piie.com/system/files/documents/pb18-14.pdf

Drath, R., \& Horch, A. (2014). Industrie 4.0: Hit or Hype? IEEE Industrial Electronics Magazine, 8(2), 56-58. https://doi.org/10.1109/MIE.2014.2312079

Ecofys. (2014). Energy storage opportunities and challenges. West Coast Perspective White Paper. Retrieved from https://www.ecofys.com/files/files/ecofys-2014-energystorage-white-paper.pdf

Energy Commission. (2015). Intelligent networks. Energy Malaysia, 6. Retrieved from http://www.ewh.ieee.org/soc/pes/malaysia/images/KeyNotePECON2010/Mohd Yusof Rakob - Planning for TNB Smart Grid.pdf

Energy Watch. (2018). Exploring rural electrification challenges in ASEAN. Retrieved from https://www.energywatch.com.my/blog/2018/04/24/exploring-rural-electrificationchallenges-in-asean/

Gaur, K., Kumar, H., Agarwal, R. P. K., Baba, K. V. S., \& Soonee, S. K. (2017). Analysing the electricity demand pattern. In 2016 National Power Systems Conference, NPSC 2016 (pp. 1-6). https://doi.org/10.1109/NPSC.2016.7858969

Goerlich, K. (2016). Internet of things: Good or bad for carbon emissions? Retrieved from https://www.digitalistmag.com/iot/2016/08/03/internet-of-things-good-or-badnews-for-carbon-emissions-04359336 
Internet Users Survey 2017. (2017). Suruhanjaya Komunikasi \& Multimedia Malaysia. Retrieved from https://www.mcmc.gov.my/skmmgovmy/media/General/pdf/ MCMC-Internet-Users-Survey-2017.pdf

Jabatan Perangkaan Malaysia. (2015). Perangkaan Ekonomi Malaysia Siri Masa 2015. Retrieved from https://www.dosm.gov.my/v1/uploads/files/3_Time Series/ Malaysia_Time_Series_2015/Penerbitan_Time_Series_2015.pdf

Jabatan Perangkaan Malaysia. (2017). Compendium of Environment Statistics 2017. Jabatan Perangkaan Malaysia. Retrieved from https://www.dosm.gov.my/v1/index. php?r=column/cthemeByCat\&cat=162\&bul_id=VTBLVkpvQVJ1QnJtMWdBcUd CTzlwZz09\&menu_id=NWVEZGhEVlNMeitaMHNzK2htRU05dz09

Jabatan Perangkaan Malaysia. (2018). Malaysia Economy 2017. Retrieved August 15, 2018, from https://www.dosm.gov.my/v1/index.php?r=column/ cthemeByCat\&cat=153\&bul_id=UXFINUwxaUVJNUFqVG5qYmtXaWRRUT09 \&menu_id=TE5CRUZCblh4ZTZMODZIbmk2aWRRQT09

Jankowski, S. (2014). The sectors where the internet of things really matters. Retrieved from https://hbr.org/2014/10/the-sectors-where-the-internet-of-things-really-matters

John, J. (2018). Amazfit verge hands on pictures: A complete premium smartwatch is born! Retrieved from https://www.gizmochina.com/2018/09/20/amazfit-verge-hands-onpictures-a-complete-premium-smartwatch-is-born/

Kearney A. T. (2015). Internet of Things, a key lever to reduce CO 2 emissions. ATKearney. Retrieved from http://www.atkearney.fr/documents/877508/879237/20151113_ IoT+Impact+on+energy_Europe+EN.pdf/6757111f-21da-49ee-82fd-915ff42dc26d

Khan, R., Khan, S. U., Zaheer, R., \& Khan, S. (2012). Future internet: The internet of things architecture, possible applications and key challenges. Proceedings - 10th International Conference on Frontiers of Information Technology, FIT 2012, 257 260. https://doi.org/10.1109/FIT.2012.53

Kushner, D. (2013). The real story of stuxnet: How Kaspersky lab tracked down the malware that stymied Iran's nuclear-fuel enrichment program. Retrieved from https:// spectrum.ieee.org/telecom/security/the-real-story-of-stuxnet/

Lasi, H., Fettke, P., Kemper, H. G., Feld, T., \& Hoffmann, M. (2014). Industry 4.0. Business and Information Systems Engineering, 6(4), 239-242. https://doi.org/10.1007/ s12599-014-0334-4

Mangruwa, R. D., Salim, S. A. Z. S., Mahdzir, A. M., \& Khalid, W. (2015). A review of cross-cultural analysis on energy behaviour consumption in residential building between Malaysia and Japan.

McCue, E. (2018). Smart cities may pave a way for a carbon-neutral future. Retrieved from http://manchesterclimate.com/news/2018/04/smart-cities-may-pave-way-carbonneutral-future

Mclellan, J. (n.d.). Automated home/energy management. Home automation, Inc. Retrieved from https://pdfs.semanticscholar.org/presentation/11ce/2dcad33b529850441efd033 bfe5f72cf8f37.pdf

Minerva, R., Biru, A., \& Rotondi, D. (2015). Towards a definition of the Internet of things (IoT). Retrieved from https://iot.ieee.org/images/files/pdf/IEEE_IoT_Towards_ Definition_Internet_of_Things_Revision1_27MAY15.pdf 
Mohanty, S. P., Choppali, U., \& Kougianos, E. (2016). Everything you wanted to know about smart cities: The internet of things is the backbone. IEEE Consumer Electronics Magazine, 5(3), 60-70. https://doi.org/10.1109/MCE.2016.2556879

Moore, G. E. (1965). Cramming more components onto integrated circuits. Electronics, 38(8), 114-117. https://doi.org/10.1109/N-SSC.2006.4785860

Moreno, M. V., Ubeda, B., Skarmeta, A. F., \& Zamora, M. A. (2014). How can we tackle energy efficiency in iot based smart buildings? Sensors, 14(6), 9582-9614. https:// doi.org/10.3390/s140609582

Orcutt, M. (2010). How a smarter grid can prevent blackouts-and cut your energy bills. Retrieved from https://www.popularmechanics.com/science/energy/a6013/how-asmarter-grid-can-prevent-blackouts/

Osman, S., Abdullah, J., \& Nawawi, A. H. (2012). Cost of urban sprawl in Malaysia. 6th International Real Estate Research Symposium (IRERS). Retrieved from http://www. inspen.gov.my/inspen/v2/wp-content/uploads/2012/05/Urban-Sprawl-In-Malaysia. pdf

Paruchuri, V. L., \& Rajesh, P. (2018). IoT for monitoring carbon monoxide (CO) emissions using wireless sensor networks in smart cities. International Journal of Engineering and Technology(UAE), 7(2), 1045-1050. Retrieved from https:/www.scopus.com/ inward/record.uri?eid=2-s2.0-85047551632\&partnerID=40\&md5=bd87c91379171f f52691935e5ba96d2f

Ponniran, A., Nur Azura, M., \& Joret, A. (2012). Electricity profile study for domestic and commercial sectors. International Journal of Integrated Engineering, 4(3), 8-12. Retrieved from http://penerbit.uthm.edu.my/ojs/index.php/ijie/article/viewFile/616/402

Rakob, M. Y. (2010). Planning for smart grid in TNB system. In IEEE Conference on Power and Energy (pp. 1-34). Retrieved from http://www.ewh.ieee.org/soc/pes/ malaysia/images/KeyNote PECON2010/Mohd Yusof Rakob - Planning for TNB Smart Grid.pdf

Ramamurthy, A., \& Jain, P. (2017). The internet of things in the power sector opportunities in Asia and the Pacific. Retrieved from https://www.adb.org/sites/default/files/ publication/350011/sdwp-48.pdf

Riley, S. (2016). Optimizing the digital factory. Software AG. Retrieved from http://www1. softwareag.com/corporate/images/SAG_Optimizing_Digital_Factory_WP_8PG_ Mar16_WEB_tcm16-125229.pdf

Rostetter, C., Khoshafian, S., \& Adams, K. (2016). The adaptive digital factory - The internet of everything in end-to-end manufacturing and product lifecycle management. Retrieved from https://www1.pega.com/system/files/resources/2018-04/prouctsmanufacturing-digital-factory-whitepaper.pdf

Russell, A. (2004). CIA plot led to huge blast in Siberian gas pipeline. Retrieved from https://www.telegraph.co.uk/news/worldnews/northamerica/usa/1455559/CIA-plotled-to-huge-blast-in-Siberian-gas-pipeline.html

Schwab, K. (2016). The fourth industrial revolution. Geneva: World Economic Forum.

SenseGrow Inc. (2015). Remote Monitoring for environmental compliance emerson process management key challenges. 
Shrouf, F., Ordieres, J., \& Miragliotta, G. (2014). Smart factories in Industry 4.0: A review of the concept and of energy management approached in production based on the Internet of things paradigm. IEEE International Conference on Industrial Engineering and Engineering Management, 2015-January, 697-701. https://doi. org/10.1109/IEEM.2014.7058728

Siemens. (2013). City climate leadership awards: Singapore - Climate close-up. Retrieved from https://www.siemens.com/press/pool/de/events/2014/infrastructurecities/2014-06-CCLA/singapore-climate-close-up.pdf

Stiner, S. (2017). IoT and energy conservation: The essentials. Retrieved from https://www. forbes.com/sites/forbestechcouncil/2017/12/14/iot-and-energy-conservation-theessentials/\#4738c8af6d1a

Suruhanjaya Tenaga. (2017a). Final energy demand by sectors. Retrieved from http://meih.st.gov.my/statistics?p_auth=W2koUdBy\&p_p_id=Eng_Statistic_ WAR_STOASPublicPortlet\&p_p_lifecycle $=1 \&$ p_p_state $=$ maximized\&p_p_ mode=view \&p_p_col_id=column-1\&p_p_col_pos=1\&p_p_col_count=2\&_Eng_ Statistic_WAR_STOASPublicPortlet_execution=e1s1\&_Eng_Stat

Suruhanjaya Tenaga. (2017b). Summary - Final energy demand. Retrieved from http:// meih.st.gov.my/STOASPublicPortlet/energystatistic/searchStatistic.oas?rptOutput= excel \&yearFrom $=1978 \&$ yearTo $=2016 \&$ productCategoryId $=6 \&$ products $=1 \&$ produc ts $=2 \&$ products $=6 \&$ products $=7 \&$ products $=8 \&$ products $=9 \&$ products $=10 \&$ products $=$ $11 \&$ products $=32 \&$ products $=33 \& \mathrm{pr}$

Talari, S., Shafie-Khah, M., Siano, P., Loia, V., Tommasetti, A., \& Catalão, J. P. S. (2017). A review of smart cities based on the internet of things concept. Energies, 10(4), 1-23. https://doi.org/10.3390/en10040421

Tejani, D., Al-Kuwari, A., \& Potdar, V. (2011). Energy conservation in a smart home. Digital Ecosystems and ..., 5(June), 241-246. https://doi.org/10.1109/DEST.2011.5936632

The internet of things in manufacturing: Benefits, use cases and trends. (2017). Retrieved from https://www.i-scoop.eu/internet-of-things-guide/internet-of-things-in-manufacturing/

Tuballa, M. L., \& Abundo, M. L. (2016). A review of the development of smart grid technologies. Renewable and Sustainable Energy Reviews, 59, 710-725. https://doi. org/10.1016/j.rser.2016.01.011

Weber, R. H. (2010). Internet of things - New security and privacy challenges. Computer Law and Security Review, 26(1), 23-30. https://doi.org/10.1016/j.clsr.2009.11.008

Xhafa, F., \& Barolli, L. (2015). Modeling and processing for next- generation big-data technologies with applications and case studies. https://doi.org/10.1007/978-3-31909177-8

Zubi, G., Dufo-López, R., Carvalho, M., \& Pasaoglu, G. (2018). The lithium-ion battery: State of the art and future perspectives. Renewable and Sustainable Energy Reviews, 89(March), 292-308. https://doi.org/10.1016/j.rser.2018.03.002 